\title{
Transition to Fluid-Induced Limit Cycle Self-Excited Vibrations of a Rotor and Instability Threshold "Hysteresis"*
}

\author{
AGNES MUSZYNSKA ${ }^{\dagger}$
}

Bently Rotor Dynamics Research Corporation, P.O. Box 2529, Minden, NV 89423-2529, USA

(Received 16 April 1998; In final form 12 June 1998)

\begin{abstract}
The transient process which starts at the instability threshold of a rotor rotating in a fluid environment, and ends up in the limit cycle of self-excited vibrations known as fluid whirl or fluid whip, is discussed in this paper. A one-lateral-mode, isotropic, nonlinear model of the rotor with fluid interaction allows for exact particular solutions and an estimation of the transient process. The fluid interacting with the rotor is contained in a small radial clearance area, such as in bearings, seals, or rotor-to-stator clearances, and its effects are represented by fluid film radial stiffness, damping, and fluid inertia rotating at a different angular velocities.

The effects of fluid damping and fluid inertia circumferential velocity ratios on the rotor startup and shutdown instability threshold differences are also discussed.
\end{abstract}

Keywords: Rotor/bearing/seal system, Fluid interaction, Fluid force model, Instability threshold, Self-excited vibrations, Transient process

\section{INTRODUCTION}

The phenomena of fluid-induced instability of rotors called fluid whirl and fluid whip have been known since 1924, as reported by Newkirk. During the last decades, many physical descriptions and models of these phenomena have been investigated. Linear models of fluid forces acting at the rotor ("bearing and seal coefficients") are the most popular due to their ease of implementation into linear rotor model computerized analyses. It is known, however, that there exist substantial discrepancies between theoretical and experimental fluid force coefficients (e.g., Myllerup et al., 1992). This poses a question of validity of the linearized modeling practices (Adams and Padovan, 1987). Linearized fluid force coefficients, most often offered in numerical/tabular formats, can provide

* This paper was originally presented at ISROMAC-7.

${ }^{\dagger}$ Tel.: 702 782-3611. Fax: 702 782-9236. E-mail: agnes $($ brdrc.com 
a base for rotor instability prediction, but do not give any realistic description of the post-instability threshold behavior of the rotor. The coefficients can hardly be associated with any practical description of the rotor/fluid interaction physical phenomena. Consequently, nonlinear models of the fluid force started gaining more attention. There is no agreement among the researchers, however, on what analytical expression for the fluid force should be adequate in specific cases. In the meantime, practical observations of the fluid-induced vibrations of machinery rotors in the field have provided rich documentation. However, in spite of the frequent occurrences of these fluid-induced vibrations, there still exists a cloud of misunderstanding of the basic physical phenomena of solid/fluid interaction in rotors (Crandall, 1983; Muszynska and Bently, 1996). This fact has considerably slowed down implementation of efficient fluid whirl/whip control mechanisms (Muszynska et al., 1988; Bently and Muszynska, 1989).

This paper is a continuation of the author's publications on the fluid-induced instabilities of rotors (Muszynska, 1986; 1988a,b; 1995; Muszynska et al., 1988; Muszynska and Bently, 1996; Bently and Muszynska, 1985; 1989; Grant et al., 1993). Through the last 15 years, extended modal testing of rotors rotating in a fluid environment (Muszynska, 1986; 1995) has provided a rich database for generalizations. It has resulted in the fluid force model which emphasizes the strength of the circumferential flow in rotor-to-stationary element radial clearances (such as in bearings, seals, blade tip/stator, impeller/diffuser) for lightly radially loaded rotors (Muszynska, 1988b; Muszynska and Bently, 1996). This model is used in this paper for the rotor within its first lateral mode to analyze the transient process from instability threshold to limit cycle of selfexcited vibrations. It is also used to investigate changes in the instability thresholds for the rotor transient process during startup and shutdown. The transition to limit cycle and instability threshold differences or "hysteresis" (the name introduced by Adams and Guo, 1996) represent new contributions to the knowledge on rotor/bearing dynamics.

\section{ROTOR/FLUID ENVIRONMENT MODEL}

\section{1.}

The mathematical model of a one-mode, isotropic rotor rotating and laterally vibrating within the fluid environment, contained in a relatively small clearance, is as follows (Muszynska, 1986):

$$
\begin{aligned}
& M \ddot{z}+D_{\mathrm{s}} \dot{z}+\left(K+K_{\mathrm{B}}\right) z+M_{\mathrm{f}}\left(\ddot{z}-2 \mathrm{j} \lambda_{\mathrm{f}} \Omega \dot{z}-\Omega^{2} \lambda_{\mathrm{f}}^{2} z\right) \\
& +\left(D+D_{\mathrm{n}}(|z|)\right)(\dot{z}-\mathrm{j} \lambda \Omega z)+f(|z|) z=0 \\
& \quad \bullet=\mathrm{d} / \mathrm{d} t, \quad z(t)=x(t)+\mathrm{j} y(t) \\
& \quad \mathrm{j}=\sqrt{-1}, \quad|z|=\sqrt{x^{2}+y^{2}}
\end{aligned}
$$

where $x, y$ are two rotor orthogonal lateral displacements, $M, K, D_{\mathrm{s}}$ are rotor first lateral mode modal mass, stiffness, and damping respectively, $K_{\mathrm{B}}, D$, and $M_{\mathrm{f}}$ are fluid radial linear stiffness, damping, and fluid inertia effect, $\lambda$ and $\lambda_{\mathrm{f}}$ are fluid circumferential average velocity ratios of rotating damping and fluid inertia forces respectively, and $\Omega$ is the rotor rotative speed. The functions $f(|z|)$ and $D_{\mathrm{n}}(|z|)$ represent the nonlinear stiffness and nonlinear damping of the fluid film, as functions of the rotor radial displacement $|z|$. These functions can have any form, provided they are continuous within the range $|z|<c$, where $c$ is the radial clearance. They cover an important class of nonlinearities; they are not, however, general.

The fluid model in Eq. (1) was identified through extensive modal perturbation testing (Muszynska, 1995; Grant et al., 1993). This model is based on the strength of the circumferential flow generated by rotor rotation. The products $\lambda \Omega$ and $\lambda_{\mathrm{f}} \Omega$ represent angular velocities at which fluid damping and fluid inertia forces respectively rotate (for classical bearing or seal stiffness coefficients $\lambda \Omega=\left(k_{x y}-k_{y x}\right) /$ $\left(D_{x x}+D_{y y}\right)$. Following research results by Bently and Muszynska (1985), Grant et al. (1993), and El-Shafei (1993), the fluid force model included the linear fluid inertia effect, which often presents a non-negligible contribution in the fluid dynamic force. Rotation of the fluid inertia force with a different rate than that of the fluid damping force 
was indicated by Ohashi (1984), Grant et al. (1993), and Muszynska (1995). Within the range of rotative speeds limited to the first lateral mode, the isotropic rotor model (1) is adequate for the case of the rotor/ bearing system (with fluid whirl and whip tendencies), rotor/seal systems (with seal fluid whip tendency), fluid handling machines with blade-tip or rotor/stator periphery interactions (with fluid whip tendencies), and rotors with press fit rotating elements, exhibiting high internal/structural friction (with internal friction whip tendencies; $\lambda \approx 1$, $\left.M_{\mathrm{f}}=0\right)$.

A justification of the use of the simple rotor model is based on the fact that the fluid-induced vibrations most often are associated with the rotor's lowest modes, either the rigid body mode (fluid whirl) or the first bending mode (fluid whip) (Muszynska and Bently, 1996). The advantage of a simple model is obvious: analytically explicit solutions allow for extended analysis and clear physical interpretations.

\section{2.}

As was shown in El-Shafei (1993), the rotor instability threshold, $\Omega_{\mathrm{st}}$, can easily be analytically calculated from the linearized Eq. (1) $\left(f=0, D_{\mathrm{n}}=0\right)$. The rotor stability criterion is as follows:

$$
\begin{gathered}
\Omega<\Omega_{\mathrm{st}} \equiv \frac{1}{\lambda}\left(1+\frac{D_{\mathrm{s}}}{D}\right) \sqrt{\frac{K+K_{\mathrm{B}}}{M+M_{\mathrm{f}} \gamma^{2}}}, \\
\text { where } \gamma=1-\lambda_{\mathrm{f}}\left(1+D_{\mathrm{s}} / D\right) / \lambda .
\end{gathered}
$$

At the instability threshold, the real part of one of the rotor system eigenvalues becomes zero, and the natural frequency $\omega_{\text {nst }}$ (the corresponding imaginary part of the eigenvalue) is equal to:

$$
\omega_{\mathrm{nst}}=\sqrt{\frac{K+K_{\mathrm{B}}}{M+M_{\mathrm{f}} \gamma^{2}}} .
$$

For the rotative speed $\Omega$ exceeding the instability threshold (2), the real part (Re) of the corresponding eigenvalue $s$ becomes positive (the remaining three eigenvalues can also be analytically calculated):

$$
\begin{aligned}
& \operatorname{Re}(s)=-\frac{D+D_{\mathrm{s}}}{2\left(M+M_{\mathrm{f}}\right)}+\frac{1}{\sqrt{2}} \sqrt{E+\sqrt{E^{2}+H^{2}}}, \\
& E=\frac{M M_{\mathrm{f}} \lambda_{\mathrm{f}}^{2} \Omega^{2}}{\left(M+M_{\mathrm{f}}\right)^{2}}+\left(\frac{D+D_{\mathrm{s}}}{2\left(M+M_{\mathrm{f}}\right)}\right)^{2}-\frac{K+K_{\mathrm{B}}}{M+M_{\mathrm{f}}}, \\
& H=\Omega\left[\frac{M_{\mathrm{f}} \lambda_{\mathrm{f}}\left(D+D_{\mathrm{s}}\right)}{\left(M+M_{\mathrm{f}}\right)^{2}}-\frac{D \lambda}{M+M_{\mathrm{f}}}\right] .
\end{aligned}
$$

The positive value of the eigenvalue real part means that the rotor lateral vibrations are unwinding; the rotor orbit represents a spiral with increasing amplitude. The particular solution of the linearized Eq. (1) has the form:

$$
z(t)=C \mathrm{e}^{\operatorname{Re}(s) t} \mathrm{e}^{\mathrm{j} \omega_{\mathrm{n}} t},
$$

where

$$
\omega_{\mathrm{n}}=\frac{M_{\mathrm{f}} \lambda_{\mathrm{f}} \Omega}{M+M_{\mathrm{f}}}+\frac{1}{\sqrt{2}} \sqrt{-E+\sqrt{E^{2}+H^{2}}}
$$

is the imaginary part of the eigenvalue, and $C$ is a constant of integration. In the case when the rotor vibration amplitude $C \mathrm{e}^{\mathrm{Re}(s) t}$ increases, the linearized model (1) ceases to be adequate, since the nonlinear factors start playing a dominant role in the rotor response as the rotor displacement amplitude grows. This causes the rate of increase of the vibration amplitude during the transient motion to decrease, until a limit cycle of the self-excited vibrations is reached.

\section{3.}

Long after early theoretical predictions of selfexcited vibration limit cycles by Poincaré and Lyapunov (Minorsky, 1947) post-instabilitythreshold limit cycles of fluid-induced, self-excited lateral vibrations of rotors have been discussed by 
Muszynska (1986, 1988a), Muszynska and Bently (1996), Malik and Hori (1986), Cheng and Mu (1996), Brown (1986), Genta and Repaci (1987), and Krynicki and Parszewski (1994).

The limit cycle of the rotor self-excited vibrations can be obtained as a particular solution of Eq. (1):

$$
z(t)=B \mathrm{e}^{\mathrm{j} \omega t},
$$

where $B, \omega$ are amplitude and frequency of the rotor self-excited vibration respectively. While Eq. (5) of the transient process represents an unwinding spiral orbit, Eq. (6) describes a circular orbit of the rotor. The amplitude $B$ and frequency $\omega$ can be calculated if Eq. (6) is substituted into Eq. (1):

$$
\begin{aligned}
- & \left(M+M_{\mathrm{f}}\right) \omega^{2}+\left[D+D_{\mathrm{s}}+D_{\mathrm{n}}(B)\right] \mathrm{j} \omega \\
& +2 M_{\mathrm{f}} \lambda_{\mathrm{f}} \Omega_{\mathrm{st}} \omega-M_{\mathrm{f}} \Omega_{\mathrm{st}}^{2} \lambda_{\mathrm{f}}^{2}+K+K_{\mathrm{B}}+f(B) \\
& -\mathrm{j} \lambda \Omega_{\mathrm{st}}\left[D+D_{\mathrm{n}}(B)\right]=0 .
\end{aligned}
$$

By splitting this equation into real and imaginary parts, two algebraic equations are generated which can be used to calculate the amplitude $B$ and frequency $\omega$ (Eqs. (2) and (3) were used):

$$
\begin{aligned}
M \omega^{2} & +M_{\mathrm{f}}\left(\omega-\lambda_{\mathrm{f}} \Omega_{\mathrm{st}}\right)^{2}-K-K_{\mathrm{B}}-f(B)=0, \\
\omega & =\frac{\lambda \Omega_{\mathrm{st}}\left[D+D_{\mathrm{n}}(B)\right]}{D+D_{\mathrm{s}}+D_{\mathrm{n}}(B)} \\
& \equiv \frac{1+D_{\mathrm{s}} / D}{1+\left(D_{\mathrm{s}} /\left(D+D_{\mathrm{n}}(B)\right)\right)} \omega_{\mathrm{nst}} \equiv \omega_{\mathrm{nst}}+\delta,
\end{aligned}
$$

where the parameter $\delta$ was introduced as:

$$
\delta=\omega_{\mathrm{nst}}\left\{\left(D / D_{\mathrm{s}}\right)+D /\left[D+D_{\mathrm{n}}(B)\right]\right\}^{-1} .
$$

For any given functions $D_{\mathrm{n}}(|z|)$ and $f(|z|)$, which now are functions of the self-excited vibration amplitude $B$, this amplitude can be calculated from Eq. (8). The limit cycle of the self-excited vibrations, known as fluid whirl or fluid whip, is, therefore, explicitly obtained. Note that the self-excited vibration frequency, $\omega$, in (8) differs only slightly from the rotor natural frequency at the instability threshold, $\omega_{\text {nst }}$, in Eq. (4).
Using Eqs. (2), (3), (8), and (9) allows for the following simplification of the first Eq. (8):

$$
\psi(\delta) \equiv \delta^{2}\left(M+M_{\mathrm{f}}\right)+2 \delta \omega_{\mathrm{nst}}\left(M+M_{\mathrm{f}} \gamma\right)=f(B)
$$

as the identity $M \omega_{\text {nst }}^{2}+M_{\mathrm{f}}\left(\omega_{\text {nst }}-\lambda_{\mathrm{f}}\left(1+D_{\mathrm{s}} /\right.\right.$ D) $\left.\omega_{\text {nst }} / \lambda\right)^{2} \equiv K+K_{\mathrm{B}}$ can be eliminated. The function $\psi(\delta)$ is a parabola, while the function $\delta=\delta\left(D_{\mathrm{n}}\right)$ (Eq. (9)) is a hyperbola. Figure 1 presents the graphical solution for $\delta$ as a function of $B$ when the nonlinear damping $D_{\mathrm{n}}(|z|) \equiv D_{\mathrm{n}}(B)$ is a given function.

Figure 2 presents the subsequent graphical solution obtained from the functions $\delta(B)$ and $\psi(\delta)$. It provides the amplitude of the self-excited vibration limit cycle when the nonlinear stiffness function $f(|z|) \equiv f(B)$ is given. This amplitude $B$ can be found at the intersection of the functions $f(B)$ and $\psi[\delta(B)]$. Since the function $\psi$ exists within the range $\left[\psi\left(\omega_{\mathrm{nst}} /\left(1+D / D_{\mathrm{s}}\right)\right)\right.$ and $\left.\psi\left(\omega_{\mathrm{nst}} D_{\mathrm{s}} / D\right)\right]$, and the function $f(B)$ exceeds these limits, the solution for $B$ must exist, as two of these function plots cross (Fig. 2).

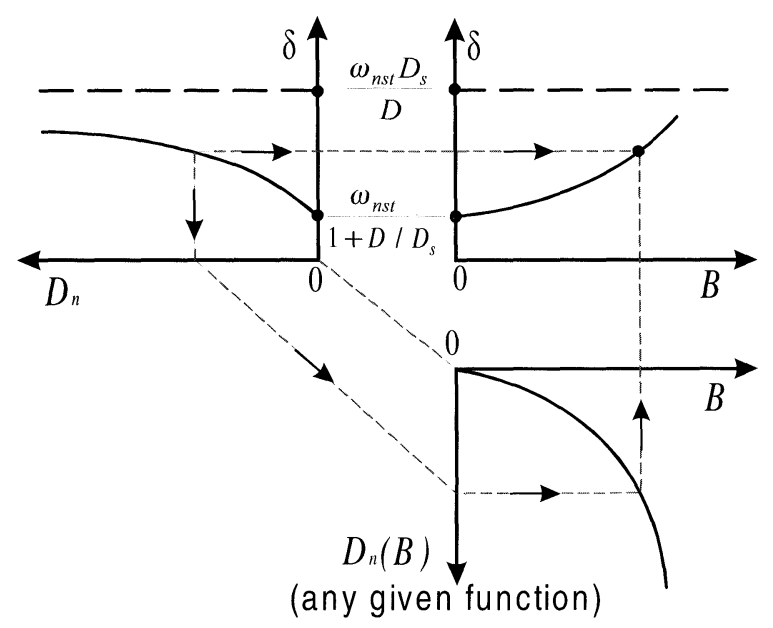

FIGURE 1 Graphical construction of function $\delta=\delta(B)$ using Eq. (9) and a given nonlinear damping function $D_{\mathrm{n}}=$ $D_{\mathrm{n}}(|z|) \equiv D_{\mathrm{n}}(B)$. 


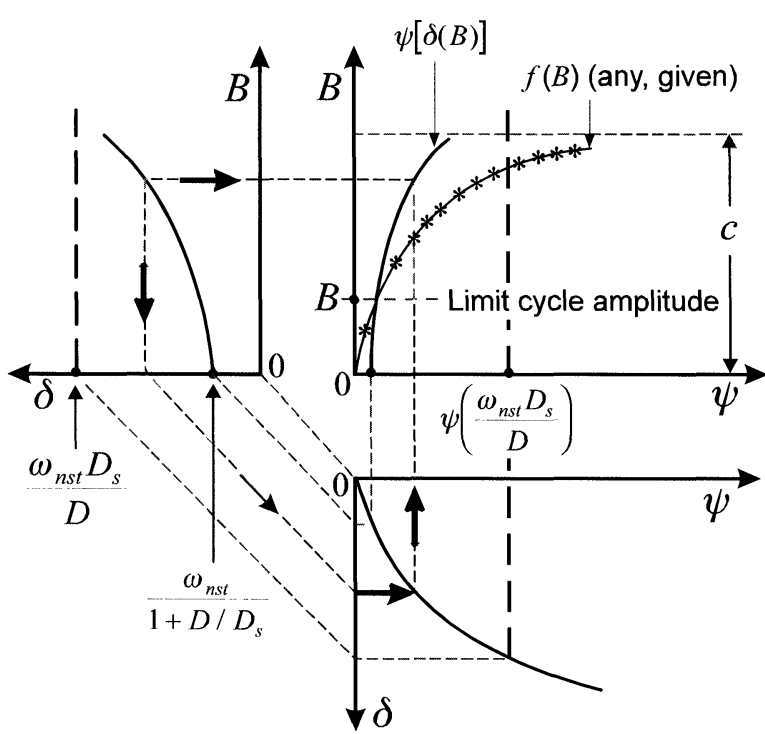

FIGURE 2 Graphical solution for the limit cycle, self-excited amplitude $B$, based on Eq. (10), function $\delta(B)$ and a given nonlinear stiffness function $f(|z|) \equiv f(B)$.

\section{TRANSIENT PROCESS STARTING AT THE INSTABILITY THRESHOLD}

The rate at which the unstable linear vibrations start unwinding, when the rotative speed reaches the instability threshold (2), can be calculated as a derivative of Eq. (4), $\partial \operatorname{Re}(s) / \partial \Omega$ at $\Omega=\Omega_{\text {st }}$, multiplied by $\Omega_{\mathrm{st}}$ :

$$
\begin{aligned}
& \left.\Omega_{\mathrm{st}} \frac{\partial \operatorname{Re}(s)}{\partial \Omega}\right|_{\Omega=\Omega_{\mathrm{st}}} \frac{D+D_{\mathrm{s}}}{\left[\frac{\left(D+D_{\mathrm{s}}\right)^{2}}{4\left(K+K_{\mathrm{B}}\right)\left(M+M_{\mathrm{f}} \gamma\right)}+1\right]\left(M+M_{\mathrm{f}} \gamma^{2}\right)} \equiv s^{*} \\
& =\frac{1}{\left[\frac{(11)}{}\right.} .
\end{aligned}
$$

At the instability threshold, the rotor unwinding spiral motion can, therefore, be presented (with approximation) as:

$$
z(t)=C \mathrm{e}^{s^{*} t} \mathrm{e}^{\mathrm{j} \omega_{\text {nst }} t} .
$$

As can be seen from Eq. (11), the real component of the exponent $s^{*}$ in the solution (12) decreases with an increase of $M, M_{\mathrm{f}}$, and $\lambda$. It increases with $K+K_{\mathrm{B}}$ and $\lambda_{\mathrm{f}}$. The role of the damping in $s^{*}$ is better seen if the fluid inertia in Eq. (11) is neglected:

$$
\left.s^{*}\right|_{M_{\mathrm{f}}=0}=\frac{D+D_{\mathrm{s}}}{\frac{\left(D+D_{\mathrm{s}}\right)^{2}}{\left(K+K_{\mathrm{B}}\right)}+\frac{2\left(M+M_{\mathrm{f}} \gamma\right)^{2}}{M+M_{\mathrm{f}} \gamma^{2}}} .
$$

This function has a maximum when $D+D_{\mathrm{s}}=$ $2 \sqrt{M\left(K+K_{\mathrm{B}}\right)}$ which resembles the critical damping. For subcritical damping, $s^{*}$ increases with a damping increase; for supercritical damping, it decreases. The above statements are also true for Eq. (11) in a qualitative sense, as some quantitative changes take place when the fluid inertia is incorporated: the maximum occurs at a smaller damping value.

\section{TRANSIENT PROCESS AROUND THE LIMIT CYCLE}

In order to evaluate the transient process around the stable limit cycle of self-excited vibrations (6) (its stability was proven by Muszynska (1988a), the variational equations will be analyzed. Eq. (1) is transformed using the following relationship:

$$
z(t)=[B+u(t)] \mathrm{e}^{\mathrm{j}[\omega t+\beta(t)]},
$$

where $\omega$ is given by the second Eq. (8) and $u(t), \beta(t)$ are real variational variables, considered small. Substituting Eq. (13) into Eq. (1), the variational equations are obtained:

$$
\begin{aligned}
& \left(M+M_{\mathrm{f}}\right)[\ddot{u}+2 \ddot{u} \mathrm{j}(\omega+\dot{\beta})+(B+u) \mathrm{j} \ddot{\beta} \\
& \left.\quad-(B+u)(\omega+\dot{\beta})^{2}\right]+\left[D+D_{\mathrm{s}}+D_{\mathrm{n}}(B+u)\right. \\
& \left.\quad-2 \mathrm{j} M_{\mathrm{f}} \lambda_{\mathrm{f}} \Omega_{\mathrm{st}}\right][\dot{u}+(B+u) \mathrm{j}(\omega+\dot{\beta})] \\
& \quad+\left\{K+K_{\mathrm{B}}-\left[D+D_{\mathrm{n}}(B+u)\right] \mathrm{j} \lambda \Omega_{\mathrm{st}}-M_{\mathrm{f}} \Omega_{\mathrm{st}}^{2} \lambda_{\mathrm{f}}^{2}\right. \\
& \quad+f(B+u)\}(B+u)=0 .
\end{aligned}
$$

The linearized equation is obtained when the functions $D_{\mathrm{n}}(B+u)$ and $f(B+u)$ are represented by the first two terms of their Taylor series, and when 
nonlinear terms in Eq. (14) are neglected:

$$
\begin{aligned}
& \left(M+M_{\mathrm{f}}\right)(\ddot{u}+2 \mathrm{j} \omega \dot{u}+\mathrm{j} B \ddot{\beta}-2 \omega B \dot{\beta}) \\
& \quad+\left(D+D_{\mathrm{s}}-2 \mathrm{j} M_{\mathrm{f}} \lambda_{\mathrm{f}} \Omega_{\mathrm{st}}\right)(\dot{u}+\mathrm{j} B \dot{\beta}) \\
& \quad+D_{\mathrm{n}}(B)(\dot{u}+\mathrm{j} B \dot{\beta})+\mathrm{j} B u D_{\mathrm{n}}^{\prime}(B)\left(\omega-\lambda \Omega_{\mathrm{st}}\right) \\
& \quad+B f^{\prime}(B) u=0,
\end{aligned}
$$

where Eq. (7) was used, and

$$
\begin{aligned}
D_{\mathrm{n}}^{\prime}(B) & \equiv \mathrm{d} D_{\mathrm{n}}(B+u) /\left.\mathrm{d}(B+u)\right|_{u=0}, \\
f^{\prime}(B) & \equiv \mathrm{d} f(B+u) /\left.\mathrm{d}(B+u)\right|_{u=0} .
\end{aligned}
$$

Splitting Eq. (15) into real and imaginary parts provides:

$$
\begin{aligned}
& \left(M+M_{\mathrm{f}}\right)(\ddot{u}-2 B \omega \dot{\beta})+\left[D+D_{\mathrm{s}}+D_{\mathrm{n}}(B)\right] \dot{u} \\
& \quad+2 M_{\mathrm{f}} \lambda_{\mathrm{f}} \Omega_{\mathrm{st}} B \dot{\beta}+u B f^{\prime}(B)=0, \\
& \left(M+M_{\mathrm{f}}\right)(2 \dot{u} \omega+B \ddot{\beta})+\left[D+D_{\mathrm{s}}+D_{\mathrm{n}}(B)\right] B \dot{\beta} \\
& \quad-2 M_{\mathrm{f}} \lambda_{\mathrm{f}} \Omega_{\mathrm{st}} \dot{u}+u B\left(\omega-\lambda \Omega_{\mathrm{st}}\right) D_{\mathrm{n}}^{\prime}(B)=0 .
\end{aligned}
$$

The characteristic equation for Eqs. (16), from which the variational eigenvalues $s_{\mathrm{v}}$ can be calculated, is as follows:

$$
\begin{aligned}
s_{\mathrm{v}}( & \left.M+M_{\mathrm{f}}\right)\left(s_{\mathrm{v}}+\frac{D+D_{\mathrm{s}}+D_{\mathrm{n}}(B)}{M+M_{\mathrm{f}}}\right)^{2} \\
+ & \left\{B f^{\prime}(B)+\frac{4}{M+M_{\mathrm{f}}}\left[M \omega+M_{\mathrm{f}}\left(\omega-\lambda_{\mathrm{f}} \Omega_{\mathrm{st}}\right)\right]^{2}\right\} s_{\mathrm{v}} \\
+ & \frac{B}{M+M_{\mathrm{f}}}\left[D+D_{\mathrm{s}}+D_{\mathrm{n}}(B)\right] f^{\prime}(B) \\
+ & \frac{2}{M+M_{\mathrm{f}}}\left[M \omega+M_{\mathrm{f}}\left(\omega-\lambda \Omega_{\mathrm{st}}\right)\right] \\
& \times\left(\omega-\lambda_{\mathrm{f}} \Omega_{\mathrm{st}}\right) B D_{\mathrm{n}}^{\prime}(B)=0 .
\end{aligned}
$$

One of the roots " $s_{\mathrm{V}}$ " is zero, and it has been extracted from Eq. (21). The analysis of the polynomial (17) shows that there exists only one real, negative root $-s^{* *}$ which is approximately equal to:

$$
\begin{aligned}
s_{\mathrm{v}} \approx & -s^{* *} \\
\equiv & -B\left\{\left[D+D_{\mathrm{s}}+D_{\mathrm{n}}(B)\right] f^{\prime}(B)\right. \\
& \left.-2\left(\lambda \Omega_{\mathrm{st}}-\omega\right)\left[M \omega+M_{\mathrm{f}}\left(\omega-\lambda_{\mathrm{f}} \Omega_{\mathrm{st}}\right)\right] D_{\mathrm{n}}^{\prime}(B)\right\} \\
& /\left\{\left[D+D_{\mathrm{s}}+D_{\mathrm{n}}(B)\right]^{2}+B\left(M+M_{\mathrm{f}}\right) f^{\prime}(B)\right. \\
& \left.+4\left[M \omega+M_{\mathrm{f}}\left(\omega-\lambda_{\mathrm{f}} \Omega_{\mathrm{st}}\right)\right]^{2}\right\} .
\end{aligned}
$$

Using Eqs. (2), (3), and (8) some terms in Eq. (18) can be transformed:

$$
\begin{aligned}
& \lambda \Omega_{\mathrm{st}}-\omega=\frac{D_{\mathrm{s}} \omega_{\mathrm{nst}}\left(D+D_{\mathrm{s}}\right)}{\left[D+D_{\mathrm{s}}+D_{\mathrm{n}}(B)\right] D}, \\
& M \omega+M_{\mathrm{f}}\left(\omega-\lambda_{\mathrm{f}} \Omega_{\mathrm{st}}\right) \\
&=\left\{\frac{M\left(1+D_{\mathrm{s}} / D\right)}{1+D_{\mathrm{s}} /\left(D+D_{\mathrm{n}}\right)}\right. \\
&\left.\quad+M_{\mathrm{f}}\left(\gamma+\frac{D_{\mathrm{s}} D_{\mathrm{n}}}{D\left(D+D_{\mathrm{s}}+D_{\mathrm{n}}\right)}\right)\right\} \omega_{\mathrm{nst}} .
\end{aligned}
$$

As can be seen from the first Eq. (19), the second term in the numerator of Eq. (18) is smaller than the first one, as it directly depends on damping $D_{\mathrm{s}}$, and can practically be neglected.

The behavior of $s^{* *}$ as a function of the system parameters is very similar to that of $s^{*}: s^{* *}$ decreases with increasing $M, M_{\mathrm{f}}$, and $\lambda$, and it increases with and $\lambda_{\mathrm{f}}$ and $f^{\prime}(B)$. The effect of $K+K_{\mathrm{B}}$ is opposite than for $s^{*}$, since now $f^{\prime}(B)$ is dominating the system stiffness.

The particular solution of Eqs. (16) is as follows:

$$
u(t)=C_{u} \mathrm{e}^{-s^{* *} t}, \quad \beta(t)=C_{\beta} \mathrm{e}^{-s^{* *} t},
$$

where $C_{u}, C_{\beta}$ are constants of integration. The solution describing the rotor motion around the limit cycle of the self-excited vibrations (6) will, therefore, be as follows:

$$
z(t)=\left(B+C_{u} \mathrm{e}^{-s^{* *} t}\right) \mathrm{e}^{\mathrm{j}\left(\omega t+C_{\beta} \mathrm{e}^{-s^{* *} t}\right)} .
$$

By comparing it with the solution (12), it can be seen that at the instability threshold the rotor amplitude exponent, which starts from the positive value $+s^{*}$, ends up, during the transition time, as the negative value $-s^{* *}$, when it reaches the limit cycle. This transition to the limit cycle of the self-excited vibration is qualitatively illustrated in Fig. 3.

\section{EXPERIMENTAL RESULTS}

Figures 4 and 5 present the full spectrum cascade plots of lateral response of a rotor (centered at rest 


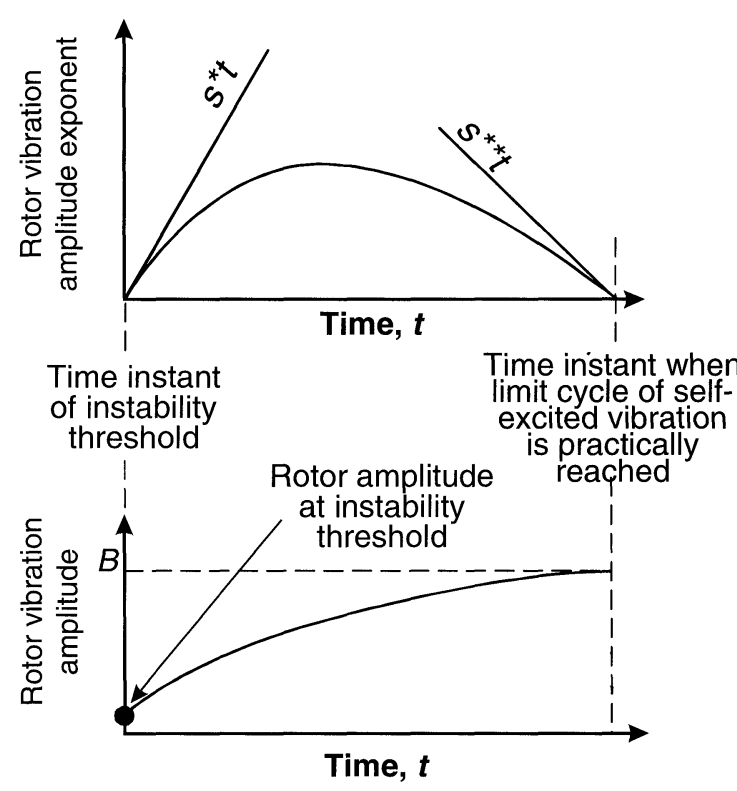

FIGURE 3 Timebase diagram of the rotor vibration transient processes between the instability threshold and the limit cycle of the self-excited vibrations.

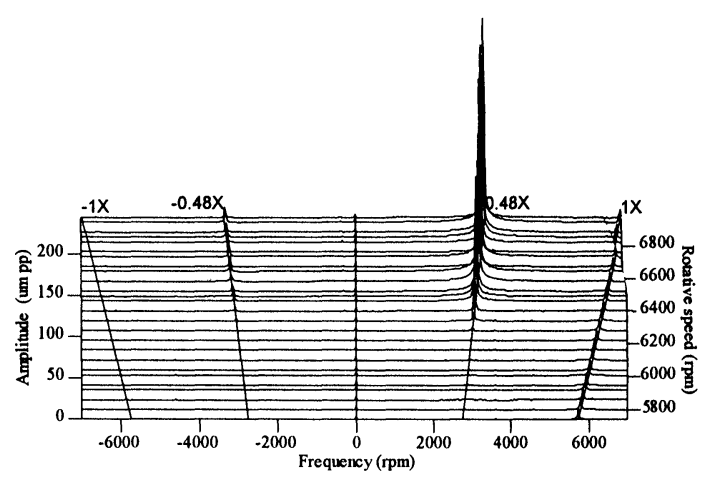

FIGURE 4 Full spectrum cascade plot of rotor response during startup with angular acceleration $3.5 \mathrm{rad} / \mathrm{s}^{2}$ (full spectrum uses data from two orthogonal transducers; elliptical orbits at each frequency component are split into circular forward and reverse components). Instability threshold occurs at $6279 \mathrm{rpm}$.

in an oil-lubricated bearing; the second bearing is relatively rigid bronze bushing) during its startup and shutdown. Details of the experimental rig can be found in references by Muszynska (1995), Muszynska and Bently (1996), and Grant et al. (1993). Due to the action of the fluid force in the bearing, the instability thresholds occur at 6279 and $6240 \mathrm{rpm}$ respectively.

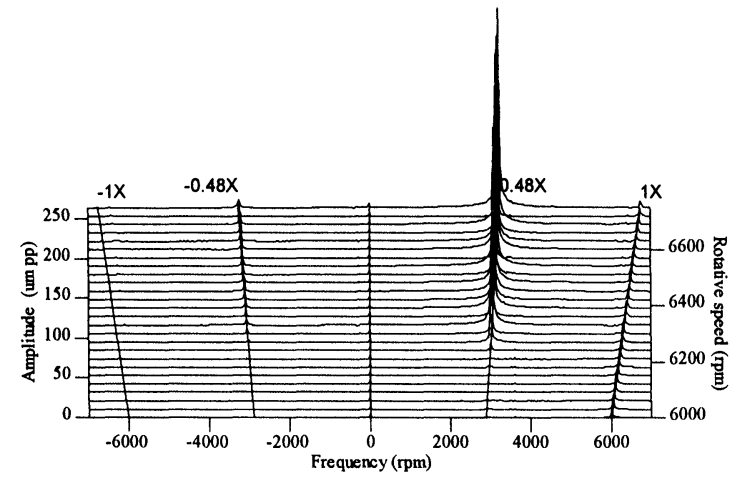

FIGURE 5 Full spectrum cascade plot of rotor response at shutdown with acceleration $-3.5 \mathrm{rad} / \mathrm{s}^{2}$. Instability threshold occurs at $6240 \mathrm{rpm}$.

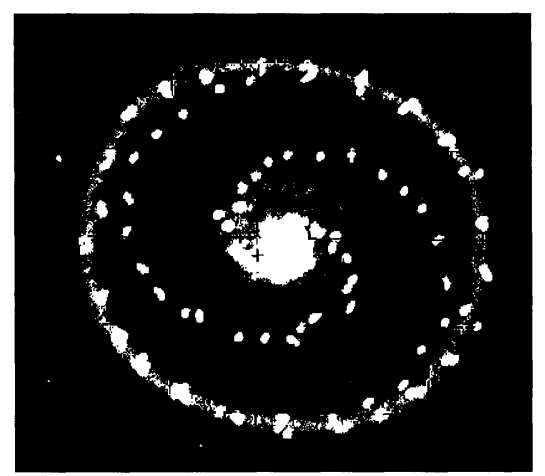

FIGURE 6 Rotor orbit between the instability threshold and limit cycle. Each bright dot represents one rotation. Picture from oscilloscope screen.

The rotor orbit in Fig. 6 illustrates the transition to the limit cycle whirl vibrations with frequency $0.48 \Omega$. Figures 4 and 5 illustrate the well-known phenomenon of "hysteresis": differences in the instability thresholds for increasing and decreasing speed. This effect was discussed and the name, "hysteresis," was introduced in by Adams and Guo (1996), but it seems that the sophisticated analysis used there is not necessary. The threshold differences increase with an increasing angular acceleration of the rotor, and can be explained using the fluid force model applied in this paper: the fluid circumferential average velocity ratio (especially that of the fluid damping force), which is driven by the rotor rotation, at startup is lagging (is smaller) 
than that during shutdown, when it is leading, in comparison to the quasi-stationary case. Another lagging/leading effect can be contributed by the fluid inertia. It was, however, less obvious in the experiments.

In order to confirm the physical observations on the "hysteresis," a specific new perturbation test was performed. An external forward rotating unbalance force at a constant frequency $\omega_{\mathrm{p}}$ was applied through an auxiliary system to the rotor during its fast startup and shutdown at $26 \mathrm{rad} / \mathrm{s}^{2}$ angular acceleration. The response of the wellbalanced rotor was filtered to the constant perturbation frequency $\omega_{\mathrm{p}}$, and presented by the Bode/ polar plots (Fig. 7). The data was then transformed into the dynamic stiffness format (Muszynska, 1995) (Fig. 8). The differences in the dynamic stiffness components for the rotor fast startup and shutdown are visible. Using the linear model (1) $\left(f=D_{\mathrm{n}}=0\right)$, these direct (DDS) and quadrature (QDS) components can be expressed as follows:

$$
\begin{aligned}
(\mathrm{DDS})= & -\left(M+M_{\mathrm{f}}\right) \omega_{\mathrm{p}}^{2}+2 M_{\mathrm{f}} \omega_{\mathrm{p}} \lambda_{\mathrm{f}} \Omega \\
& -M_{\mathrm{f}} \lambda_{\mathrm{f}}^{2} \Omega^{2}+K+K_{\mathrm{B}}, \\
(\mathrm{QDS})= & \left(D+D_{\mathrm{s}}\right) \omega_{\mathrm{p}}-D \lambda \Omega .
\end{aligned}
$$

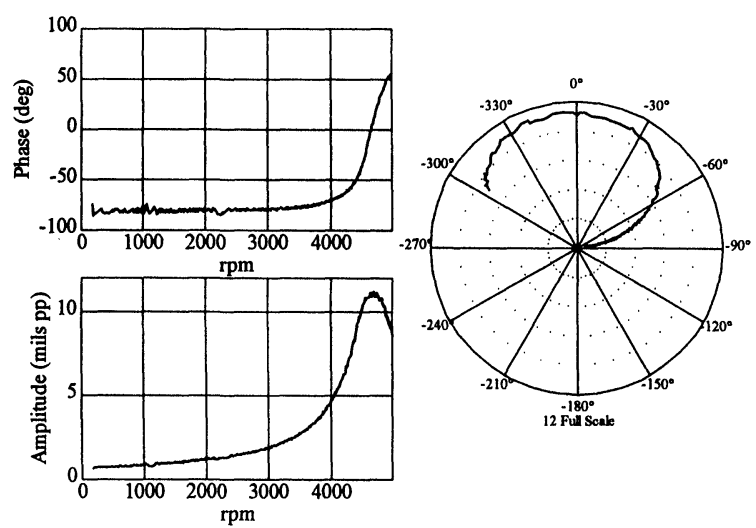

FIGURE 7 Well-balanced rotor startup (a) and shutdown (b) vertical responses filtered to perturbation frequency $\omega_{\mathrm{p}}=2250 \mathrm{cpm}$ in Bode and polar format versus rotative speed. Rotor angular acceleration was $26 \mathrm{rad} / \mathrm{s}^{2}$. The fluid whirl resonances $\Omega=\omega\left(1+D_{\mathrm{s}} / D\right) / \lambda$ (Muszynska, 1995) occurring at $\Omega=4877 \mathrm{rpm}$ (startup) and $4653 \mathrm{rpm}$ (shutdown) are well pronounced.
Note in Fig. 8 that the direct stiffness does not have a constant value for $\omega_{\mathrm{p}}=$ const. This indicates that DDS depends on the fluid inertia which involves the rotative speed $\Omega$. The differences, $\Delta$, in the dynamic stiffness components for the startup minus shutdown are:

$$
\begin{gathered}
\Delta(\mathrm{DDS})=-M_{\mathrm{fu}}\left(\omega-\lambda_{\mathrm{fu}} \Omega\right)^{2}+M_{\mathrm{fd}}\left(\omega_{\mathrm{p}}-\lambda_{\mathrm{fd}} \Omega\right)^{2}, \\
\Delta(\mathrm{QDS})=D \Omega\left(\lambda_{\mathrm{u}}-\lambda_{\mathrm{d}}\right),
\end{gathered}
$$

where indexes $\mathrm{u}$ and $\mathrm{d}$ denote startup and shutdown respectively. From Fig. 8 and Eq. (24), the fluid damping force average circumferential velocity ratios can be identified: $\lambda_{\mathbf{u}}=0.484$, $\lambda_{\mathrm{d}}=0.471$. The ratio $\lambda_{\mathrm{u}}$ for startup is, therefore, about $2.6 \%$ lower than that for shutdown for this example of the rotor high angular acceleration. Note that the difference between $\lambda_{\mathrm{u}}$ and $\lambda_{\mathrm{d}}$ can by itself explain the instability threshold (2) differences, as the instability threshold $\Omega_{\mathrm{st}}$ is a
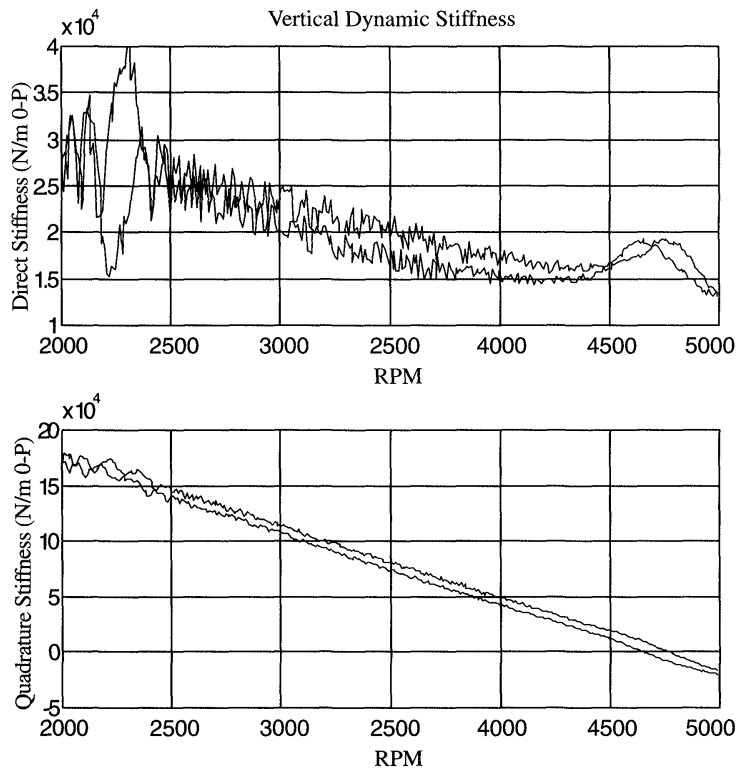

FIGURE 8 Rotor startup and shutdown direct (DDS) and quadrature (QDS) dynamic stiffness components versus rotative speed. Humps in DDS at fluid whirl resonance speed are due to stiffness nonlinearity (Muszynska, 1995). 
decreasing function of $\lambda$. The relationship between $\Omega_{\mathrm{st}}$ and the fluid inertia ratio $\lambda_{\mathrm{f}}$ has a peak value when $\lambda_{\mathrm{f}}=\lambda /\left(1+D_{\mathrm{s}} / D\right)$. Since a direct identification of $\lambda_{\mathrm{f}}$ is not possible, qualitative analysis of the effect of $\lambda_{\mathrm{f}}$ on the startup/shutdown characteristics is made taking into account the instability threshold and direct dynamic stiffness information. In order to concentrate attention on the fluid inertia effect, an assumption is made below that in the instability thresholds for the startup and shutdown (Eq. (2)) $\lambda_{\mathrm{u}}=\lambda_{\mathrm{d}}=\lambda$ and $D_{\mathrm{s}}=0$. Using notation (3), it results, therefore, in

$$
M_{\mathrm{fd}} / M_{\mathrm{fu}}>\left[\left(\lambda-\lambda_{\mathrm{fu}}\right) /\left(\lambda-\lambda_{\mathrm{fd}}\right)\right]^{2} .
$$

On the other hand, Eq. (23) and perturbation results (Fig. 8) provide another inequality:

$$
M_{\mathrm{fd}} / M_{\mathrm{fu}}>\left[\left(\omega_{\mathrm{p}}-\lambda_{\mathrm{fu}} \Omega\right) /\left(\omega_{\mathrm{p}}-\lambda_{\mathrm{fd}} \Omega\right)\right]^{2} .
$$

The right-side expressions of (25) and (26) are concave, crossing parabolas versus $\lambda_{\mathrm{fu}}$, which define the lower border of the area of possible $M_{\mathrm{fd}} / M_{\mathrm{fu}}$ ratios (Fig. 9). If $\lambda_{\mathrm{fu}}=\lambda_{\mathrm{fd}}$, then $M_{\mathrm{fd}}>M_{\mathrm{fu}}$, which seems unlikely. If $M_{\mathrm{fu}}=M_{\mathrm{fd}}$, then $\lambda_{\mathrm{fu}}$ is limited: $\left[\max \left(2 \lambda-\lambda_{\mathrm{fd}}, 2 \omega_{\mathrm{p}} / \omega-\lambda_{\mathrm{fd}}\right)<\right.$ $\lambda_{\mathrm{fu}}<\lambda_{\mathrm{fd}}$ ] (provided that $\lambda_{\mathrm{fd}}$ is high enough, $\left.\lambda_{\mathrm{fd}}>\max \left(\lambda, \omega_{\mathrm{p}} / \Omega\right)\right)$. Note that for the fluid resonance conditions $\left(\omega_{\mathrm{p}}=\lambda \Omega\right)$ both inequalities (25) and (26) are the same. So far the evidence is still

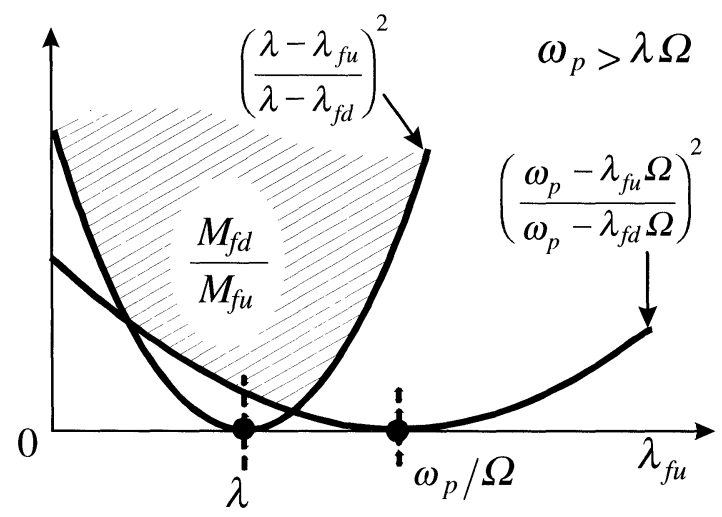

FIGURE 9 Area of possible ratios of the shutdown and startup fluid inertia ratio, $M_{\mathrm{fd}} / M_{\mathrm{fu}}$, versus fluid inertia circumferential average velocity ratio at startup, $\lambda_{\mathrm{fu}}$ insufficient to conclude about the variability of the fluid inertia during the startup and shutdown of the rotor. The research on this subject continues.

\section{SUMMARY AND CONCLUSIONS}

As the first subject, the post-instability threshold behavior of rotors rotating in fluid environment enclosed in small radial clearances was discussed in this paper. The nonlinear fluid force model identified by Muszynska (1988b, 1995), Muszynska and Bently (1996), and Grant et al. (1993), using the modal perturbation testing during the past 15 years, was implemented into the first lateral mode of an isotropic rotor. The equations provide analytical values for the instability threshold, and the limit cycle self-excited vibration amplitude and frequency. The transient process starting at the instability threshold, and ending at the limit cycle, was evaluated analytically and illustrated experimentally. As the second subject, the differences in the instability thresholds for rotor startups and shutdowns, known as a "hysteresis" (Adams and Guo, 1996), were presented and discussed (the "hysteresis" here does not have any correlation to energy loss). The sole differences in the rates of the fluid damping rotation rate $(\lambda)$ explain the basic portion of this hysteresis. These differences are very well intuitively understood, and can easily be quantified by the novel perturbation testing: the external perturbation rotating force with a constant amplitude and frequency is applied to the rotor during its startup and shutdown transition. The rotor response filtered to the perturbation frequency is then presented in the dynamic stiffness format, which makes parameter identification easy. The effect of the fluid inertia on the instability "hysteresis" was also evaluated, but quantitatively it remains inconclusive. The discussed two subjects represent new contributions. The applied fluid force model, based on the strength of circumferential flow, once again proved to be useful and adequate in describing the physical phenomena occurring in rotors in a fluid environment. 


\section{NOMENCLATURE}

\author{
$B, \omega$ \\ $c$ \\ $D, K_{\mathrm{B}}, M_{\mathrm{f}}$ \\ $D_{\mathrm{n}}(|z|), D_{\mathrm{n}}^{\prime}$ \\ $D_{\mathrm{s}}, K, M$
}

DDS, QDS

$f(|z|), f^{\prime}$

$\mathrm{j}=\sqrt{-1}$

$\operatorname{Re}()$

$s, s_{\mathrm{V}}$

$s^{*}, s^{* *}$

$t$

$u(t), \beta(t)$

$z(t)=x(t)+\mathrm{j} y(t)$

$\delta=\delta\left(D_{\mathrm{n}}\right)$

$\gamma=1-\lambda_{\mathrm{f}}\left(1+D_{\mathrm{s}} / D\right) / \lambda$

$\lambda, \lambda_{\mathrm{f}}$

$\psi=\psi(\delta)$

$\omega_{\mathrm{n}}, \omega_{\mathrm{nst}}$

$\omega_{\mathrm{p}}$

$\Omega$

$\Omega_{\mathrm{st}}$

Indexes:
Limit cycle self-excited amplitude and frequency Bearing radial clearance Fluid radial damping, stiffness, and fluid inertia respectively.

Fluid nonlinear damping function and its derivative Rotor first lateral mode modal damping, stiffness, and mass

Direct and Quadrature dynamic stiffness of the system

Fluid nonlinear stiffness function and its derivative

Real part

Eigenvalues

Tangent estimates of the transient process to the limit cycle

Time

Variational variables

Rotor lateral

displacements

Eq. (9)

Eq. (2)

Fluid circumferential average velocity ratios for fluid damping and fluid inertia forces

Eq. (10)

Natural frequency and natural frequency at instability threshold Perturbation frequency Rotative speed Instability threshold u: startup, d: shutdown

\section{References}

Adams, M.L. and Guo, J.-S. (1996) Simulations and experiments of the nonlinear hysteresis loop for rotor/bearing instability, C500/001/96, IMechE, Proc. 6th Int. Conf. On Vibrations in Rotating Machinery, Oxford, UK

Adams, M.L. and Padovan, J. (1987) Insights into linearized rotor dynamics, Journal of Sound and Vibration, 76(1), 1981, Part 2, 112(1)

Bently, D.E. and Muszynska, A. (1985) Identification of bearing and seal dynamic stiffness parameters by steady-state load and squeeze film tests, NASA CP 2409, pp. 301-316.

Bently, D.E. and Muszynska, A. (1989) Anti-swirl arrangements prevent rotor/seal instability, Trans. of $A S M E J V A S \& R D$, 111(2), 156-162.

Brown, R.D. (1986) Sub-synchronous limit cycles for a flexible shaft in lobed hydrodynamic bearings, Proc. Int. Conf. On Rotordynamics, IFToMM, Tokyo, pp. 211-216.

Cheng, S.C. and Mu, H.P. (1996) The limit cycle characteristics analysis of oil film instability whirl with Hopf-bifurcation method, Proc. ISROMAC-6, Vol. 1, Honolulu, Hawaii.

Crandall, S. (1983) The Physical Nature of Rotor Instability Mechanisms, Rotor Dynamical Instability, ed., M.L. Adams, ASME, AMD-V. 55.

El-Shafei, A. (1993) Modeling Fluid Inertia Forces in Short Journal Bearings for Rotordynamic Analysis, Vibration of Rotating Systems, eds., K. Wang and D. Segalman, ASME, DE-V. 60.

Genta, G. and Repaci, A. (1987) Circular Whirling and Unbalance Response of Nonlinear Rotors, Rotating Machinery Dynamics, ASME DE-V. 2, Boston, Massachusetts, pp. 441-448.

Grant, J., Muszynska, A. and Bently, D.E. (1993) Parameter identification of a rotor supported in a pressurized bearing lubricated with water, Proc. 7th Workshop on Rotordynamic Instability Problems in High Performance Turbomachinery, Texas A\&M, College Station, Texas.

Krynicki, K. and Parszewski, Z.A. (1994) Post-stability attenuation of rotor-bearing systems, Proc. IFToMM, Fourth Int. Conf. On Rotor Dynamics, Chicago, Illinois, pp. 281-286.

Malik, M. and Hori, Y. (1986) An approximate nonlinear transient analysis of journal bearing response in unstable region of linearized system, Proc. Int. Conf. On Rotordynamics, IFToMM, Tokyo, Japan, pp. 217-220.

Minorsky, N. (1947) Introduction to Non-Linear Mechanics, J.W. Edwards, Ann Arbor, Michigan.

Muszynska, A. (1986) Whirl and whip - rotor/bearing stability problems, Journal of Sound and Vibration, 110(3), $443-462$.

Muszynska, A., Franklin, W.D. and Bently, D.E. (1988) Rotor active "anti-swirl" control, Trans. of ASME, JVAS\&RD, 110(2), 143-150.

Muszynska, A. (1988a) Stability of whirl and whip in rotor/ bearing systems, Journal of Sound and Vibration, 127(1), 49-64.

Muszynska, A. (1988b) Improvements in lightly loaded rotor/ bearing and rotor/seal models, Trans. of ASME, JVAS\&RD, 110(2), 129-136

Muszynska, A. (1995) Modal testing of rotors with fluid interaction, International Journal of Rotating Machinery, 1(2), 83-116. 
Muszynska, A. and Bently, D.E. (1996) Fluid-induced instabilities of rotors: whirl and whip - summary of results, Orbit, 17(1), 7-15.

Myllerup, C.M., Tonnesen, J. and Lund, W. (1992) On the discrepancies between experiment and theory for a cylindrical fluid film journal bearing considering steady-state and journal dynamic characteristics, Proc. IMechE Vibrations in Rotating Machinery Conf., Bath, UK.

Newkirk, B.L. (1924) Shaft whipping, GE Review, 27.

Ohashi, H. (1984) Lateral fluid forces acting on a whirling centrifugal impeller in vaneless and vaned diffuser, NASA CP 2338, pp. $109-122$. 


\section{ait \\ ENERGY MATERIALS}

M A N E Y publishing

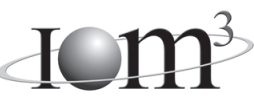

\section{Materials Science \& Engineering for Energy Systems}

Maney Publishing on behalf of the Institute of Materials, Minerals and Mining

The Institute of Materials, Minerals \& Mining

Economic and environmental factors are creating ever greater pressures for the efficient generation, transmission and use of energy. Materials developments are crucial to progress in all these areas: to innovation in design; to extending lifetime and maintenance intervals; and to successful operation in more demanding environments. Drawing together the broad community with interests in these areas, Energy Materials addresses materials needs in future energy generation, transmission, utilisation, conservation and storage. The journal covers thermal generation and gas turbines; renewable power (wind, wave, tidal, hydro, solar and geothermal); fuel cells (low and high temperature); materials issues relevant to biomass and biotechnology; nuclear power generation (fission and fusion); hydrogen generation and storage in the context of the 'hydrogen economy'; and the transmission and storage of the energy produced.

As well as publishing high-quality peer-reviewed research, Energy Materials promotes discussion of issues common to all sectors, through commissioned reviews and commentaries. The journal includes coverage of energy economics and policy, and broader social issues, since the political and legislative context influence research and investment decisions.

\section{CALL FOR PAPERS}

Contributions to the journal should be submitted online at http://ema.edmgr.com

To view the Notes for Contributors please visit: www.maney.co.uk/journals/notes/ema

Upon publication in 2006, this journal will be available via the Ingenta Connect journals service. To view free sample content online visit: www.ingentaconnect.com/content/maney

For further information please contact:

Maney Publishing UK

Tel: +44 (0)113 2497481 Fax: +44 (0)1132486983 Email: subscriptions@maney.co.uk

or

Maney Publishing North America

Tel (toll free): 8662975154 Fax: 6173546875 Email: maney@maneyusa.com

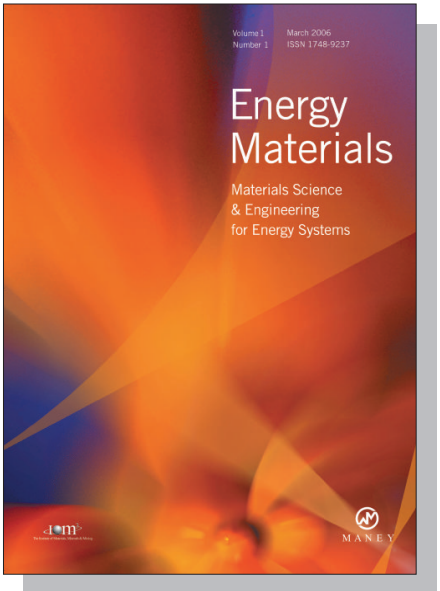

EDITORS

Dr Fujio Abe

NIMS, Japan

Dr John Hald, IPL-MPT, Technical University of Denmark, Denmark

Dr R Viswanathan, EPRI, USA

\section{SUBSCRIPTION INFORMATION}

Volume 1 (2006), 4 issues per year

Print ISSN: 1748-9237 Online ISSN: 1748-9245

Individual rate: $£ 76.00 / U S \$ 141.00$

Institutional rate: $£ 235.00 /$ US $\$ 435.00$

Online-only institutional rate: $£ 199.00 / U S \$ 367.00$

For special $\mathrm{IOM}^{3}$ member rates please email

subscriptions@maney.co.uk

\section{For further information or to subscribe online please visit www.maney.co.uk}



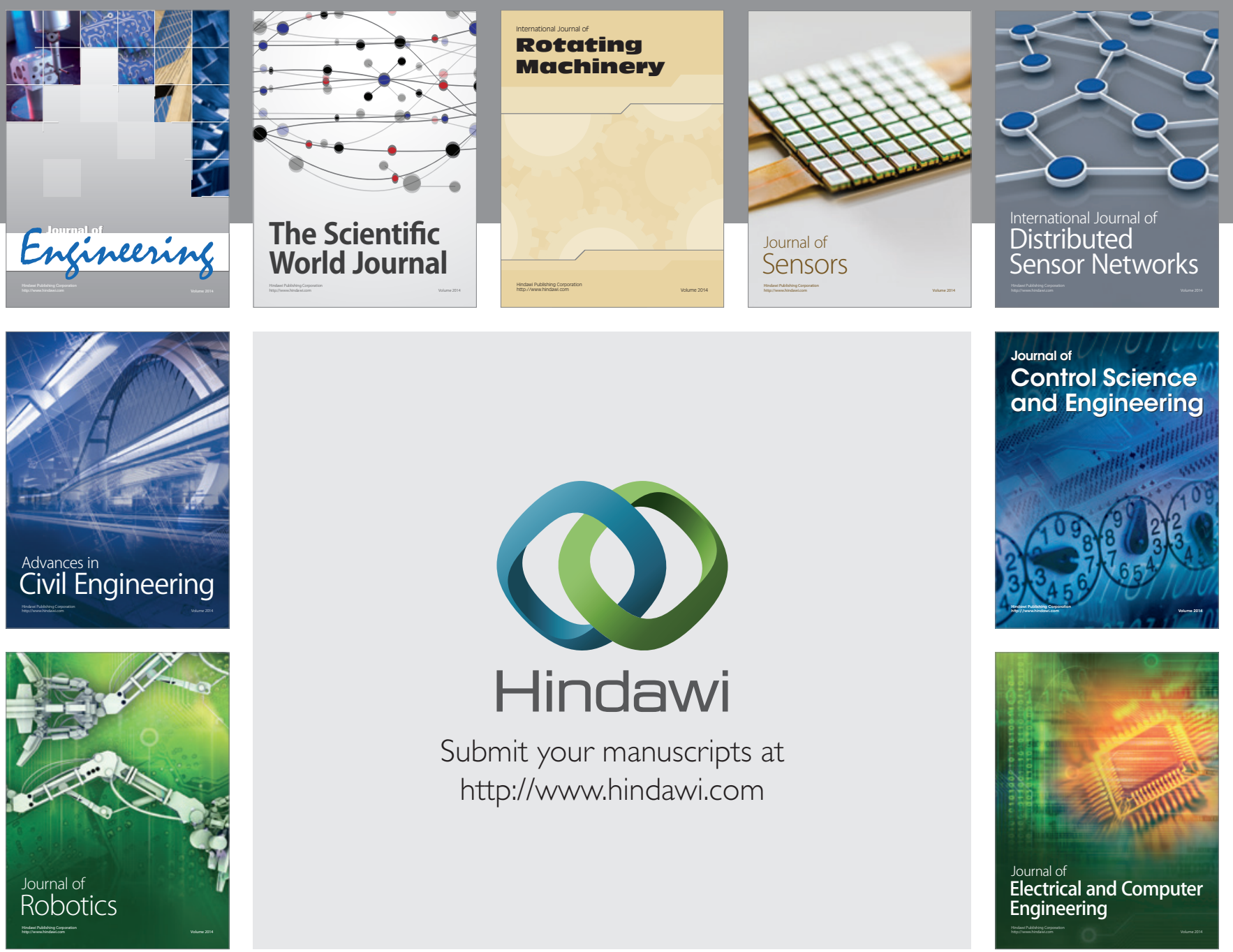

Submit your manuscripts at

http://www.hindawi.com
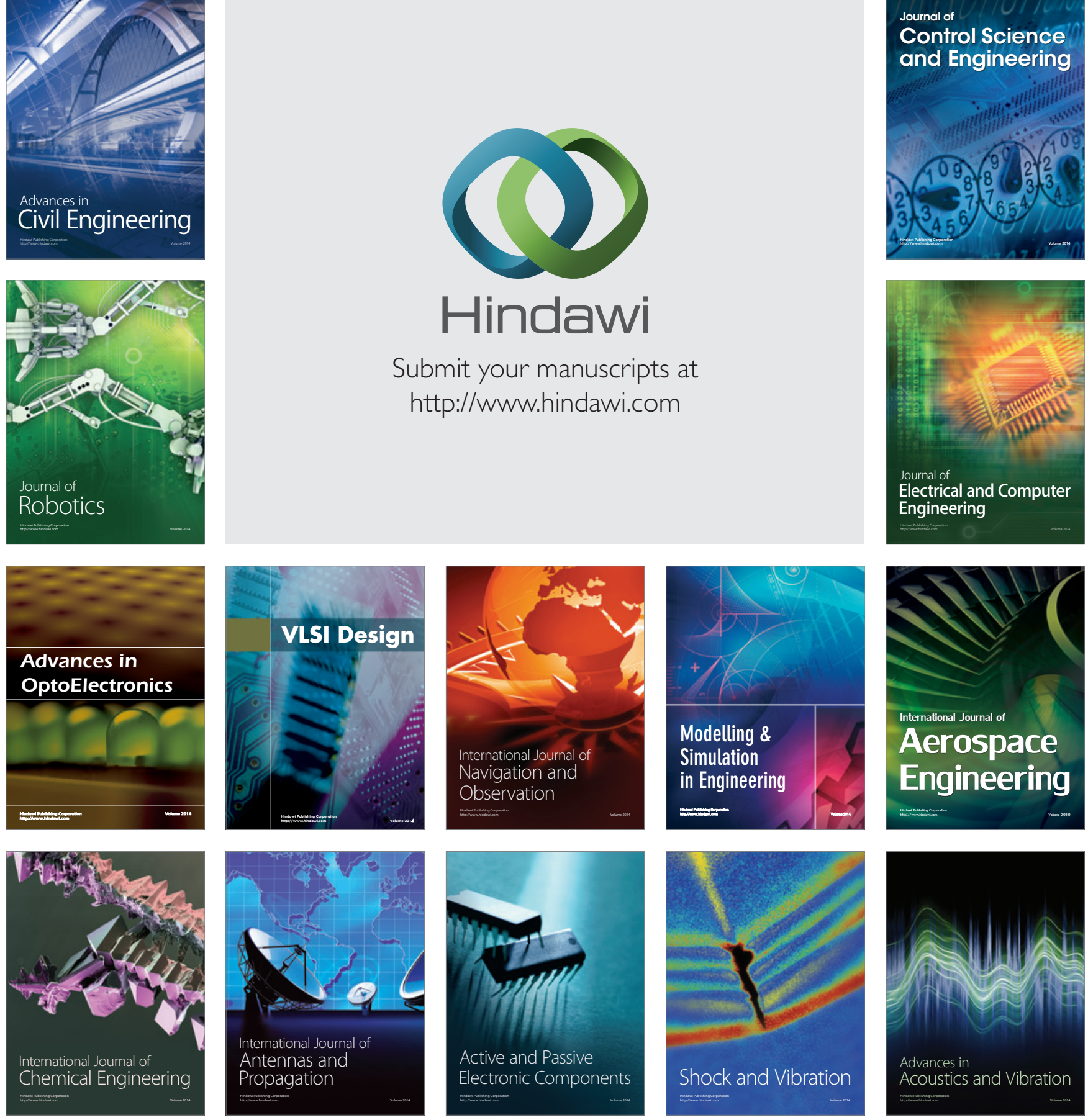